\title{
User, carer and professional experiences of care in motor neurone disease
}

Janice B Brown School of Nursing and Midwifery, University of Southampton, Southampton, UK

\begin{abstract}
Motor neurone disease (MND) is a devastating neurological terminal condition with no cure. Care is the only option, which sharpens the need for its examination and clarification. This paper reports on a hermeneutic study which addressed the question, 'What are the lay and professional values of care in the context of motor neurone disease and is there a difference between them which affects care delivery and receipt?' The study discovered three ways of caring, with most alignment between the two lay groups. The professional carer stance is predominantly functional and illustrates detachment from the experience of living with illness whereas the recipients' needs are holistic. These two value structures, the mechanistic and the hermeneutic, are in tension. To redress this imbalance, support for a dispositional shift in professional values to be more client focused is advocated.
\end{abstract}

Key words: experiences in care; hermeneutics; motor neurone disease; neurological disability; user, carer and professional care experiences

\section{Introduction}

Three people die of motor neurone disease (MND) in the UK everyday and there are 5000 people living with MND at any one time (MNDA, 2000). It is a devastating disease that leaves people unable to walk, talk, eat or drink. Their intellect remains intact so they are conscious of their own deterioration, up until death. The needs they present will range from aspects of progressive immobility, bulbar palsy and its associated swallowing difficulties, insufficient nutritional input and communication problems to reduced respiratory effort, fear and uncertainty. Many of these needs are similar to those of people suffering from a range of neurological conditions inclusive of multiple sclerosis, Parkinson's disease, stroke and brain stem infarctions. However, in MND there is no clear causation, no remission, steady deterioration and no curative treatment. Death is inevitable within an approximate time frame of two to five years. Examining caring in this context is investigating at

Address for correspondence: Dr Janice B Brown, School of Nursing and Midwifery, Nightingale Building 67, University of Southampton, Southampton, UK. Email: jbc1@ soton.ac.uk the edge of human endurance and illuminates the very 'being' of care.

This paper reports on the experiences of caring from the perspectives of six people with MND, six 'lay' carers and a 'team' of nine professionals. A hermeneutic phenomenological approach facilitated investigation into the worlds of these three groups. Gained insights into their different experiences contribute to the knowledge base of the experiential trajectory in MND and to caring practice in the context of neurological disability.

\section{Background to caring}

Over the last 20 years, examination of the concept of caring in health and social care has been pursued by a large number of researchers (Blustein, 1991; Campbell, 1984; Dalley, 1988; Kitson, 1993; Leininger, 1988; Morse et al., 1990; Nolan and Grant, 1989; Roach, 1992; Watson, 1985). Although it may be acknowledged that caring takes many forms and is delivered by members of different professions as well as lay groups, nursing has made particular claims that caring is the essence of nursing (Benner and Wrubel, 1989; Bishop and Scudder, 1991). While this may be a legitimate claim, it also echoes ownership and exclusivity 
which may be seen as a divisive concept to pursue in a multiprofessional, multiagency environment of health and social care where the patient is the central player (DoH, 2000).

Both qualitative (Clarke and Wheeler, 1992; Yam and Rossiter, 2000) and quantitative approaches (Arthur etal., 2001; Watson et al., 1999) have been used to examine caring. Paley (2001: 189) concludes that, despite all these studies, our understanding and knowledge base of caring remains 'elusive, complex, ambiguous or vague'. Endless lists of caring descriptions and attributes, associations, and 'things said' about caring from various groups and perspectives have resulted in a knowledge base which Paley (2001: 195) claims is 'quite literary, useless'. In defence of this argument, the claim is based on the perceived impossibility of testing these descriptive findings and/or applying them to practice. A counter argument is that efforts to understand perceptions and experiences of care can inform future practice and that knowledge of care experiences can influence and change practice. The 'purity' of such knowledge may not be measurable in a technical-rational sense but is certainly transferable and influential in developing sensitive, clientfocused practice. Evidence is growing that educational programmes to promote caring practices (Hoover, 2002; Murray, 1998; Wikstrom, 2001) are making a difference to students' capacity to be caring practitioners. These programmes may include examples of patients' experiences of illness, and in the case of MND draw on work specifically concerned with MND (Beresford, 1995; Oliver, 1995; Robinson and Hunter, 1998; Small and Rhodes, 2000).

Understanding experiences of living and caring in MND is pivotal to appreciating the devastating effect that MND has on patients and carers, and also on professional carers. This study provides evidence which enhances such understanding and contributes to the implementation of sensitive, appropriate care provision.

\section{Purpose and aim of the study}

The purpose of this study is to gain understanding of caring experiences in MND in order to contribute to further development of caring policy and practice. The aim of the study is to answer the research question, 'What are the lay and professional values of care in the context of MND and is there a difference between them which affects care delivery and receipt?'

\section{Research approach}

Application of the principles of phenomenology and hermeneutics is congruent with seeking a greater understanding of meanings of experience and phenomenon, inclusive of care. Heidegger's (1962) phenomenology offers an interpretive enquiry focus into 'being in the world' of motor neurone disease. The term hermeneutic traditionally refers to the interpretation of texts (Outhwaite, 1987). Heidegger (1962) draws on hermeneutics as his approach for questioning and analysing such being, and Gadamer (1975) develops Heidegger's hermeneutic stance further through his metaphors of prejudice, hermeneutic circle, fusion of horizons and historicity. In this combination, the premise is that interpretation is a universal requisite for all understanding; it presupposes prior understanding and so it is only possible to interpret according to one's own lived experiences. This principle has been applied to the interpretative analysis of the evidence gained from the participants but also applies to the reader of the ensuing paper. This means that generalizations are not claimed from the study but data is presented for the reader to assess a sense of resonance and therefore possible application to their own particular area of practice.

Heidegger used the concept of fore-structure (prejudice) to explain that one's past experiences and beliefs cannot be denied in interpretation. Indeed, this was one of the driving forces behind the study, as the researcher had experienced caring for people with MND as a sister on a neurological ward and was intrigued by the differences in care practices between service users and professionals. Walters (1995) suggests that to accommodate this interpretive feature it is necessary for the researcher to reflect continually on their involvement and possible changing perspective during a study. This principle was upheld throughout the study through the maintenance of a journal to promote reflexivity on the process.

\section{Sample}

Ethical committee approval to conduct the study was secured and recognition of the sensitive nature of the issues to be investigated guided the research 
Table 1 Profile of MND participants

\begin{tabular}{|c|c|c|c|c|}
\hline & Sex & Age & $\begin{array}{l}\text { Relationship } \\
\text { to lay carer } \\
\text { in study }\end{array}$ & $\begin{array}{l}\text { Occupation } \\
\text { of cared for }\end{array}$ \\
\hline MND1 & Male & 69 & Husband & $\begin{array}{l}\text { Retired from } \\
\text { Telecommunications }\end{array}$ \\
\hline MND2 & Female & 49 & No relation & Hairdresser \\
\hline MND3 & Male & 40 & Husband & Council employee \\
\hline MND4 & Female & 38 & Wife & Secretary \\
\hline MND5 & Female & 69 & Wife & Housewife \\
\hline MND6 & Female & 54 & Wife & $\begin{array}{l}\text { Healthcare } \\
\text { professional }\end{array}$ \\
\hline
\end{tabular}

process. People with MND were recruited through the Motor Neurone Disease Association (MNDA). The researcher was invited to present her proposals to a local group and these were subsequently advertised in their local newsletter. People with a confirmed diagnosis of MND and a willingness to talk about their experiences were invited to volunteer to take part. They were asked to identify their main lay carer $(n=6)$. In five of the six cases this was their spouse. One spouse declined and one person with MND declined at the point of the first interview. The latter's partner still wished to continue in the study. One pair identified one professional team as offering 'good practice'. This team $(n=9)$ was invited to join the study and agreed. The profiles of the three groups are located in Tables 1-3.

Table 2 Profile of lay carer participants

\begin{tabular}{|c|c|c|c|c|}
\hline & Sex & Age & $\begin{array}{l}\text { Relationship } \\
\text { to MND }\end{array}$ & $\begin{array}{l}\text { Occupation } \\
\text { of lay carer }\end{array}$ \\
\hline LC1 & Female & 60 & Wife & $\begin{array}{l}\text { School } \\
\text { teacher }\end{array}$ \\
\hline LC2 & Male & 73 & No relation & $\begin{array}{l}\text { Retired } \\
\text { industrial } \\
\text { manager }\end{array}$ \\
\hline LC3 & Female & 38 & Wife & $\begin{array}{l}\text { Part-time } \\
\text { dinner lady }\end{array}$ \\
\hline LC4 & Male & 40 & Husband & Architect \\
\hline LC5 & Male & 73 & Husband & $\begin{array}{l}\text { Retired } \\
\text { policeman }\end{array}$ \\
\hline LC6 & Male & 55 & Husband & $\begin{array}{l}\text { Senior civil } \\
\text { servant }\end{array}$ \\
\hline
\end{tabular}

Table 3 Profile of professional carer participants

\begin{tabular}{|c|c|c|c|}
\hline & Sex & Occupation & Case experience \\
\hline PC1 & Female & $\begin{array}{l}\text { Speech and } \\
\text { language therapist }\end{array}$ & approx 5 cases \\
\hline PC2 & Female & $\begin{array}{l}\text { Nurse specialist, } \\
\text { disability }\end{array}$ & approx 3 cases \\
\hline PC3 & Female & District nurse & First case \\
\hline PC4 & Female & Dietician & First case \\
\hline PC5 & Female & Social worker & First case \\
\hline PC6 & Female & General practitioner & First case \\
\hline PC7 & Female & Physiotherapist & Many cases $>10$ \\
\hline PC8 & Male & $\begin{array}{l}\text { Neurological } \\
\text { consultant }\end{array}$ & $\begin{array}{l}\text { Multiple cases > } \\
100\end{array}$ \\
\hline PC9 & Female & $\begin{array}{l}\text { Occupational } \\
\text { therapist }\end{array}$ & Many cases $>10$ \\
\hline
\end{tabular}

\section{Data collection}

Two guided conversations spaced at threemonthly intervals were conducted with participants. Conversations lasted between 60 and 90 min each, were audiotaped and transcribed verbatim. The primary question posed at the first conversation was, 'What is it like to have MND/care for a person with MND?' This was to gain a sense of their experiences in care. The secondary question was, 'Are your thoughts concerning caring changed as a result of experiencing caring?' This was to gain any sense of transformation of their meaning of care from being actively engaged in its practice. Before the second conversation, participants received a copy of the transcript, from their first conversation, to check for accuracy.

The focus of the second conversation was threefold: to correct any transcription mistakes; share the interpretive analysis in the form of first level themes; and to establish if any further experiences had led to a change or modification in their thinking about care.

\section{Data analysis and interpretation}

Hermeneutic analysis does not lend itself to a fixed process. Through the application of the principles of hermeneutic phenomenology, and in support of academic rigour, a five-stage analysis process was developed (Clarke, 1999). However, the analysis decision trail is a vital component for establishing the rigour of a study.

Stage 1 began with deeply engaging, reading and writing a summary of the participants' stories as understood by the researcher. Stage 2 began the 
interpretation through questioning the text in terms of what was being meant by the stories, what was happening here? Significant statements were extracted to answer these questions and they were clustered into first-level themes. At stage 3, the themes were taken to the second conversation to gain a 'fusion of meaning' (Gadamer, 1975) between researcher and participant. The researcher presented the themes by stating this is what I understand you were meaning, this is what I learnt from you - do you agree? Misinterpretations were rare but when corrected, mutual understanding was gained and further learning achieved by the researcher. Stage 4 involved establishing second level themes from the confirmed first-level themes. Any corrected elements from the second conversation were included. Themes from each participant were then clustered with their group to build group categories. Three distinct group experiential accounts were plotted within a temporal trajectory. The final stage (Stage 5) involved comparing categories across the three groups for similarities and differences. Identification of similarities and differences in caring between users, carers and professionals became the basis for developing professional learning recommendations.

\section{Findings}

Presenting large amounts of qualitative data in a paper is always a challenge, therefore resultant categories from the three groups are presented in 'maps' with quotations and interpretations. In each group, the categories are presented in a particular order to illustrate the changes experienced over time.

\section{Experiences of people with MND}

Eight categories were identified from the MND participants. These are diagrammatically presented in Figure 1. The starting point of users' experiences is the shock of their symptoms, realization that their body is failing prematurely, their existence is threatened and their sense of self is beseiged. This realization is captured in the category existential shock as the participants' reported losing confidence in their bodies, recognizing their physical vulnerability and being scared of facing their imminent death. Many of their symptoms were personally frightening such as difficulties

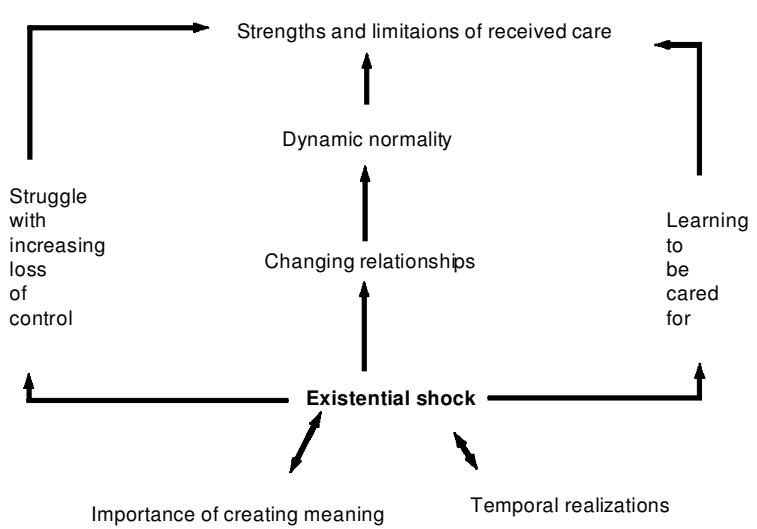

Figure 1 Interrelationship between the categories from participants with MND.

swallowing, expressive speech problems, hands and feet not obeying commands. These symptoms often progressed without a clear diagnosis.

Their experiences suggested that not knowing the diagnosis was stressful but on securing a diagnosis their shock deepens, in terms of the uncertainty of what to expect from the disease and the length of life remaining; 'It's horrible, it's the worst thing I can remember. Not knowing how long you've got. Not knowing where you' re going, how you are going to be and not having any guidelines' (MND2). The course of MND for each individual is uncertain in terms of location of muscle deterioration and timescale. The patients knew every 'case' was unique and that professionals were unable to state causes, outcomes and timeframes. This reality made the disease harder to fight against as; 'when they say they don't know what causes something you've got no goal to fight against ... it's very hard to fight against something when you don't know what you're fighting against' (MND2).

While they were trying to deal with the shock of having MND, they tried to make sense of it, understand how they had developed it and create meaning in terms of what may had caused it. They read widely and became quite 'expert' in the disease and its progression. This confirmed their temporal realizations that their lifespan was now short and their active lifespan even shorter. The knowledge of their disease deepened their existential shock but as their symptoms increased, they began struggling with increasing loss of control.

Loss of control pervaded all aspects of their 
lives. Bodily deterioration coupled with a loss of social and communication outlets forces a person to turn inward, to face death in an increasingly difficult day to day life. These quotations illustrate the challenges faced in trying to maintain a sense of self;

You never like to think you are incapable of doing something and relying on somebody else... You're annoyed ... because there are so many things you can't do, things you used to be able to do and now you can't. I know certain things I am not going to be able to do again and that's upsetting .... There's nothing really I can do apart from watch television.

(MND1)

However, determination initially keeps the struggle in progress, 'What a way to die, bit by bit like a crushing ivy killing off a healthy tree. I have a lot to do for my family before the last clutches of the deadly ivy zaps the last bit of sap' (MND6). However, the relentlessness of MND means that it eventually begins to win, 'it's really taken over our lives' (MND3), to the extent of imposing exhaustion and depression as; 'I'm getting very fed up with being ill, there's no respite' (MND2).

At first sight it may be considered surprising that one has to learn how to be cared for. This category captures how MND forces people to learn new skills and a new way of 'being'. The MND participants did not like being cared for as they experienced loss of privacy and control and greater vulnerability. Being cared for requires learned expressions of gratitude and tolerance, even when they are resisting their situation, but these 'learned ways of being' are necessary to promote carers to continue their support.

Initially, they had to learn to accept they needed help, 'I've been a very independent person and it's hard to accept help' (MND2). People discovered their physical deterioration meant necessary interventions of being washed, shaved, dressed, fed and eventually using a wheelchair. One dread was 'not coping in the loo ... a tremendous fear' (MND6), which was closely followed by the prospect of being bedridden. These feelings of vulnerability and loss of privacy led to an overall dislike of being cared for. This was coupled with learning about the effects of losing independence and their own emotional labour, 'I don't really like it ... I've always been able to do things for myself and relying on other people I don't really like. I have to be more tolerant' (MND3).

User emotional labour was not confined to learning about physical interventions as deteriorating communication ability presented them with enormous frustrations, 'when you've not been understood, that's really one of the hardest things' (MND6).

They had to learn to adapt to a range of carers and found it unsettling to have to react to differing personalities and styles of care. Learning to be cared for involved a transformation of 'being'. They had to learn 'how' to receive care in the physical sense and the psychological sense of learning 'gratitude and tolerance' towards others for attending to their vulnerability and passivity. They had to learn much about loss in terms of their rights and independence, almost in preparation for their loss of life.

Changing relationships occurred during the process of physical deterioration. Wives and husbands became 'nurses', friends stopped coming to see them, and speech deficits stifled conversations. Roles changed for the surviving partners, who had to acquire their partners' duties as well as their own. Children had to learn about loss. One participant, while talking about his children explained that as his disease progressed, 'I feel that I am leaving and that they are mourning my death' (MND3).

The concept of 'normality' was abandoned, but episodes of coping permitted families to find stability that allowed them to recharge. There was a notion of dynamic normality, which can be described as 'everything the same but not the same but trying to keep the same'. Dynamic normality is illustrated by the experience of one family striving to maintain family meals. At first the wife fed the husband using a spoon, then set up the enteral feeding routine, until finally the dynamic normality collapsed as the husband remained in the lounge during 'family' meal times. The children were unable to tolerate the 'difference' any longer.

Through their experiences, people with MND were able to judge the strengths and limitations of the care they received from others. They valued the functional interventions from professionals who knew about equipment, mobility, feeding and breathing techniques. They valued qualities of carers who were respectful, made them feel valued, 
and offered them time and consideration. They did not appreciate the lack of continuity of carers, lack of co-ordination among the professionals or the lack of emotional care.

One person reported, 'on the whole, they've been very supportive and kind but mostly people are frightened and detached. There's not many people who want to be involved personally' (MND4).

\section{Carers' experiences}

Nine categories were identified from conversations with carers (Figure 2). In congruence with their partners, they suffered shock, which is captured in the category of destabilizing impact. Their future together and their sense of security and normality was shattered through the diagnosis. Fear was a predominate emotion coupled with a sense of dread of the future. This has resonance with their partner's 'existential shock', illustrated by 'I hate it. I hate it. It takes away your future. It's kind of gone' (LC3 wife). Her future dreams and expectations are dashed as she realizes she has to cope with watching her husband die rather than sharing a life together. A husband reports being 'Shattered, because it's pulled me down' but acknowledges how it must be faced as 'you mustn't try to hide it and think that it's going to go away because it's not' (LC5).

Carers also wanted to create meaning about the situation and searched for answers about the cause and effect of MND. They appreciated through temporal realizations that they might only have

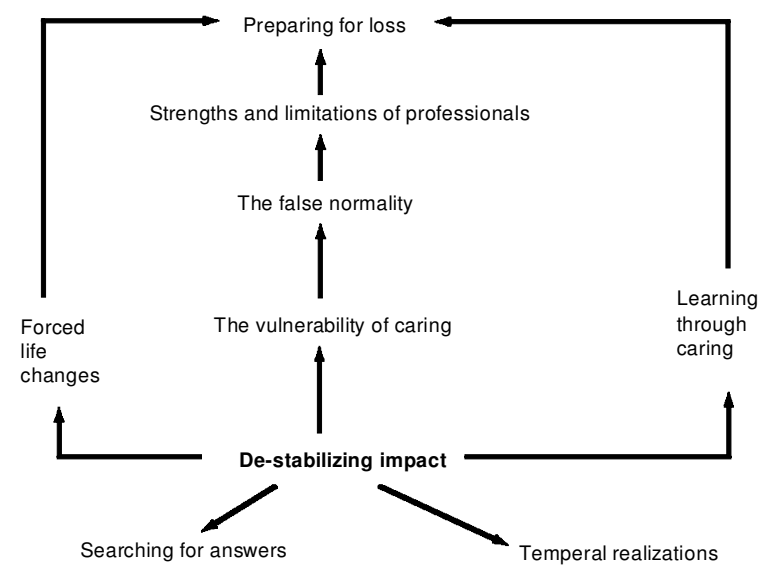

Figure 2 Interrelationship between the categories from LC participants. their partner alive for a few months or years under difficult circumstances.

The 'vulnerability of caring' category captures the ongoing suffering and emotional distress experienced by the carers 'This is horrible. It's worse than cancer' (LC2), 'I hate it. I hate it' (LC3). Their social network became reduced due to communication difficulties. Dinner invitations and friendship stopped. Professionals did not attend regularly which deepened isolation as, 'I used to go weeks and sometimes months before I saw anybody, I mean the social worker was five or six weeks sometimes' (LC5).

There was no evidence of any care professional being directly allocated to support the carer. However, the 'need for moral support' (LC5) was clearly identified as caring is 'damned hard work'. (LC2). 'I'm suffering an emotional upset at the same time as caring, so as far as doing the job I'd just be me, ... I'm emotionally upset by it all so that's the added stress and stain, it's not just caring, it's suffering' (LC3). Coupled with responsibility made them realize that, 'I don't think I could ever be ill now. I don't know what we'd do' (LC2).

Carers also experienced a false normality when they tried to establish a sense of coping through deliberate routines. They experienced forced life changes as a change in circumstance in one partner created a change in the other. Increased responsibilities was closely correlated with progressive deterioration caused by MND. Jobs, hobbies, friends all went as caring became a full time job. There were some positive outcomes in terms of learning new skills but more frequently the experiences were never-ending hard work, resulting in exhaustion. Their gradient in learning through caring was steep. They had to learn practical as well as emotional aspects of care. 'I know what it's like now to have to care for someone. I just feel sorry for everybody who has to do it' (LC2). Their caring was motivated by love but required new ways of 'being'. It was demanding, exhausting and required physical and emotional investment of self. They also identified strengths and limitations of professionals. They were well supported in being taught the functional skills of using equipment for mobility and feeding activities. However, there were limitations in professional co-operation and team working as these two quotes illustrate. 'It's just weaving it together for my wife, (which) clearly is the difficulty' (LC6) and '(we) used to 
have half a dozen professional faces and I just couldn't place them all and I never knew which one to speak to' (LC4). Equally, carers felt insufficiently cared for themselves, particularly in terms of emotional support. They felt professionals worked in a rather detached manner, 'I think it's all talked about mainly in a business like manner rather than in an emotional way' (LC5).

Thinking about life after your partner's death is uncharted territory for most people and presents a sensitive area of enquiry. However, there was evidence that carers were preparing for loss as the inevitability of death was accepted but their own futures were uncertain; 'It's a dreadful situation for me, very frightening ... I think he has given up. Now it's very near... you have to accept it' (LC1). However, few partnerships talked about the future of the carer, probably because it was such a difficult issue.

Two exceptions were LC4 who had tried to reassure his wife not to worry about their young son and LC5 who reported that they had discussed everything and 'it was her idea that when she died, I have a holiday'.

LC3 recognized how her attitude changed over time. She had achieved some of her grieving and was preparing to think of her life again, 'I don't know whether it's like compassion, when you've seen enough terrible pictures you kind of switch yourself off and how when you recognize that you can't do anything about it you've got to try and concentrate on your life more'. She even gave away all her MND books, almost as if she realized she had to give her husband away to MND.

Work and career were obvious needs for LC4 and LC6 as they struggled to continue with their careers during their partners' illness. 'I'd love to do my job and look after Liz but what do I do when Liz's gone and there's no job and probably a five year void in my career. A future employer wouldn't really want to take a risk'. They both maintained their jobs throughout their partners illness albeit with modifications in role and time.

\section{Professional experiences}

Analysis of conversations with professional carers generated seven categories (Figure 3). Commonalties of caring outweighed differences among the nine professionals. Professional carers do not have the same level of involvement, invested time, emotional interplay, physical hands on or potential loss when compared with the person with MND and their partner. Their starting point was identification of their strengths, which involved their respective functional interventions. However, seven professionals also highlighted their sense of genuine involvement through wanting to 'know' the patients and carers and acknowledged the importance of continuity of professionals.

The speech and language therapist told how being 'a counsellor is very important, to be a listener ... I tend to be there to soak it all up 'cos sometimes they need to offload and you've actually got to take on their burden of grief' (PC1).

The physiotherapist was well aware of the impact MND has on people's lives, in all its dimensions. She stated, 'that although you can't stop it happening, you can't stop it getting worse, you can do an awful lot to make it better while it's happening ... by altering one slight thing that situation has improved matters for the family' (PC7).

The district nurse identified her role as holistic as 'I'm checking his pressure areas, arms and things. I'm there for him really. I get him food (parental nutritional packs), I'm there to talk to

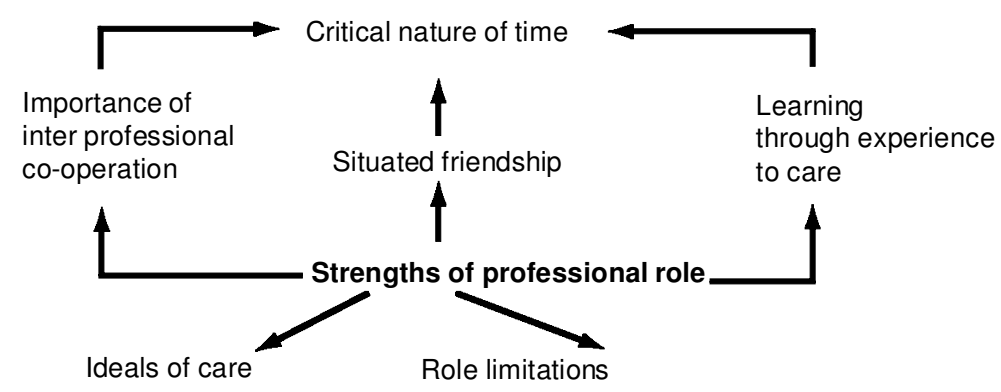

Figure 3 Interrelationship between the categories from PC participants. 
them if they want me, setting up the emergency pack, making sure that he's got everything that he needs' (PC3).

The level of experience with MND varied between the professionals. Six of the nine were facing their first case of MND (see Table 3). The inexperienced read predominantly from MNDA sources and textbooks. The district nurse stated, 'I don't know that much about motor neurone disease, it's a difficult one, so many things that could go wrong, I'm just thinking "help!" I read as much as I could'.

The GP acknowledged uncertainty about MND, 'I had to admit to him my lack of knowledge and how I'm sort of learning as he was'... 'he wanted my opinion on it [taking the drug Riluzole] and I couldn't give him that 'cos I hadn't had any experience of it' (PC6). However, many functional skills were transferable to MND patients as the physiotherapist suggests, 'the problems that we deal with are [the same] for lots of people, mobility problems ... the actual problems are things we are quite used to, it's more the psychological, social problems that perhaps makes MND unique'.

Professionals in the study regarded lay carers as vital players as 'it's all down to the carer, all down to the family and they're having to do so much ... it's the carer that does most of the work'. Indeed the district nurse admitted that, 'I suppose I tended to concentrate more on his wife because I think she's doing a brilliant job looking after him' (PC3). The social worker also promoted the importance of the lay carer, as 'if the carer goes down, the whole thing generally collapses' (PC5). Professionals talked of their ideals of care, which encompassed the practice of biomedical ethical principles, holism and engaging with human beings to reduce suffering. This category captures how they strove to practice through their ideals as they valued people within a moral foundation. It underpinned their practice even when practical concerns dominated.

Role limitations were perceived as an uncomfortable admission. Two main areas were identified: the functional limitations inclusive of lack of personnel, time and equipment and the external economics which affected care delivery. These led to frustrations for the care professionals due to a limited ability to achieve their ideals of care. Professionals reported adjusting their demeanour and broadening their value perspectives to meet those of the patient; trying to fit in with their lifestyles and stance; using emotional effort to be responsive to patient needs and keeping the focus on the patient. The category of situated friendship arose from professional carer motivations of "wanting to provide the best that there is ... as a friend' (PC3). Friendship invites a level of commitment, a motivation to locate the other person's frame of mind and to respond to their needs. It is 'situated' as the friendship originates from the diagnosis and only lasts while the care is being delivered. It was not an ideal of care but an action of professional caring.

Time was a critical factor in the level of friendship attained. Five of the professionals who spent most time with clients agreed it resulted in a closer relationship with the primary focus on the needs of the patient. Professionals did not expect a reciprocal arrangement as 'part of being a professional is being able to disengage your own personal feelings ... I have to find the best way that they want me to interact with them really' (PC5).

Situated friendship requires a reflexive demeanour, trying to adjust to the patient's mood and temperament. The importance of trying to emotionally 'fit' with patients rather than be in contrast with them was recognized, 'I mean I might be feeling lousy, like I have this morning and I've been putting on a beam [smile] everywhere' (PC3). Similarly, it was acknowledged that moving from one patient to another becomes quite a challenge. You may be 'having to be very serious and very sad and perhaps going to someone who's completely opposite and it's hard then to quickly change from being one type of person to another type of person' (PC7). Their 'emotional labour' was considered effective in promoting and sustaining a situated friendship but the professionals in this study accepted that this value was not true for all professionals. You hear about situations when 'patients have come across when somebody hasn't adapted and that's when clashes happen' (PC7).

The critical nature of time was recognized from two perspectives. Firstly, from the patient's limited life expectancy but also in their own frustrations in gaining equipment or financial support for additional care resources. Professionals acknowledged that they continue to learn through experiences to care. This included learning from patients, using active listening, being attentive and having an openness to learn about the needs of others. 
They also tried to share their learning in this group of professionals as they recognized the importance of interprofessional co-operation. They collectively met as a case management group but identified how this was not common practice in the care of people with MND.

\section{Discussion and conclusion}

The findings of this study offer evidence of differences, predominantly between the stances of lay and professional carers in MND. The variations in the starting points of their journeys and subsequent progression illustrate different value standpoints between care deliverers and recipients. The professionals begin their stories recounting their positive functional aspects: the strengths of their role. Listening and hearing patients' stories to appreciate their existential shock and the destabilizing influence of MND did not feature. Only when professionals had exhausted their functional contribution did they consider their ideals and aspirations. However, as we have seen, both the users and carers begin their stories identifying their extreme threat and shock. These two different starting points in the experience of the disease trajectory suggest hermeneutic and mechanistic stances. The client view does not diminish the need for functional interventions but highlights a gap in the professional sense of support and care focus.

The central value for people with MND was the need to be valued and treated as 'being human'. MND steals one's mobility, speech, bulbar function and general independence; all features of being human. It does not steal one's intellect but this can be rendered externally latent through the communication deficit. Physical deterioration and loss of personal control combined with learning about the indignities of being cared for and facing certain death, force relational values to become paramount as people search for expression of their 'humanness' through others.

The central value of carers is manifest through the caring they can offer, often motivated by the love they have for their partner but closely associated with their own suffering. As they try to remain strong and motivated to cope with caring they also have to face making changes to their own lives. They have much to learn: firstly, how caring is hard work, becomes a full time job and forces life changes of great magnitude to the extent that one's former life is lost. These elements can create personal distress and highlight their vulnerability, which increases tension as they are concerned about what would happen to their partner if they themselves became ill. Equally, the silver lining is that they may learn new skills and gain a greater sense of confidence and competence in these caring.

The professional carers' central value lies in reducing suffering. Professionals appreciate the debilitating effects of MND but their practice prioritizes their functional roles over emotional support. This situation is often created through external constraints but leaves professionals in a constant state of tension. The need for professionals and carers to interact with people with MND as 'being human in extremis' cannot be overemphasized. Keeping the focus on the person rather than the disease appears so simple, yet so challenging. Strategies to support this imperative are promoting the understanding and recognition that MND is a terminal disease as well as a chronic condition.

From the terminal perspective, early referrals (Goodman et al., 1998) to the community and palliative care team would be most supportive for people with MND and their families. However, asking professionals to emotionally engage with patients as well as functionally operate has considerable implications for their educational preparation and ongoing professional support. An example of this need is reported by Ray et al. (1996), who reveals that some physicians actively avoid forming relationships as they consider it may affect their decision making and ability to remain objective.

The more positive view of early referrals and forming relationships could be that more individualized care could be offered, planning could be more proactive and symptom management more effective. Also, the case for extending early specialist palliative services to noncancer patients is clearly made (Field and Addington-Hall, 1999) although people with nonmalignant diseases are often not seen as suitable candidates for palliative care until they have been defined as 'terminal'. The label 'terminal' encourages professionals to prioritize services and care delivery (Goodman et al., 1998) whereas the chronic aspect alone can 
marginalize patient care (Thorne etal., 2000; Twigg, 1997).

Chronic illness remains a challenge to a health service familiar with acute and critical care as 'chronic illness is an inherently different social enterprise' (Thorne et al., 2000: 304). In acute and critical care the disease and cure are the priorities and offer the professionals a high degree of detachment coupled with timely success and achievement. Even in terminal care, professionals can gain a sense of role satisfaction over a finite time period. However, in chronic care the emphasis is on enduring care, complex care and requires different skills with less immediate or obvious 'success'. As MND lies astride the terminal and chronic categories it can be argued that it specifically challenges professionals and services. This uneasy interface may confuse professionals as to how they should respond and may contribute to the mismatch between patient and professional priorities, resulting in many professionals turning to their more traditional focus, the disease rather than the person.

More recently, policy is directing proactive patient involvement in their care and selfmanagement through recognizing the expert patient (DoH, 2001). This can be viewed as a welcome development to promote a shift in the balance of care control to patients and will surely influence professional behaviour. However, Wilson (2001) warns as to whether healthcare professionals will accept and acknowledge the patients as 'expert'. Education is a key transformer and Stott et al. (1996) report how they were able to promote diabetic patients involvement in their management with nurses, and moderately influence physicians through education, group discussions and consultation feedback. However, to support this process we need to educate professionals differently, not just focus our attention on educating patients and leave them with the burden of change.

It seems that policy shifts harnessed with lay and professional education strategies are all significant drivers necessary to bring about a social transformation of really placing the focus of care on the person and promoting a balance between the mechanistic and hermeneutic perspectives.

This paper has examined experiences in caring as disclosed by people in the world of MND. Three separate group experiences are presented as illustrations of their similarities and differences ident- ified in this context. These findings are supportive of a need to examine the benefits of a dispositional shift in professional values to be more client and interprofessionally focused. Professionals need support for this change, as it is a social development as well as professional. Policy shifts and professional education are supportive routes incorporating active user and carer involvement together with interprofessional and multiagency co-operation.

The findings presented in this study have not been tested in the experimental sense. However, presentations to people with MND, their lay carers and professionals have been met with a strong sense of resonance. This itself has offered users and carers a sense of warmth and hope that professionals are concerned with improving their caring practices in MND. Professionals have also identified how the outcomes have parallels to other disease trajectories (multiple sclerosis, CVA and other nonmalignant terminal diseases). Similar work in these areas could highlight these connections explicitly and identify particular values of importance that may serve to influence practice perspectives and educational programmes.

\section{References}

Arthur, D., Pang, S. and Wong, T. 2001: The effect of technology on the caring attributes of an international sample of nurses. International Journal of Nursing Studies 38, 37-43.

Benner, P. and Wrubel, J. 1989: The primacy of caring. Reading, MA: Addison-Wesley.

Beresford, S. 1995: Motor neurone disease. London: Chapman and Hall.

Bishop, A.H. and Scudder, J.R. 1991: Nursing: the practice of caring. New York: National League for Nursing.

Blustein, J. 1991: Care and commitment. Oxford: Oxford University Press.

Campbell, A. 1984: Moderated love. Theology of professional care. London: SPCK.

Clarke, J. 1999: Hermeneutic analysis: a qualitative decision trail. International Journal of Nursing 36, 363-69.

Clarke, J.B. and Wheeler, S.J. 1992: A view of the phenomenon of caring in nursing practice. Journal of Advanced Nursing 17, 1283-90.

Dalley, G. 1988: Ideologies of caring. Basingstoke: Macmillan.

Department of Health 2000: The NHS plan. London: DOH.

Department of Health 2001: The expert patient. London: DOH.

Field, D. and Addington-Hall, J. 1999: Extending specialist palliative care services to all? Social Science and Medicine 48, $1271-80$. 
Gadamer, H. 1975: Trust and method. In: Barden, G. and Cumming, J. editors, New York: Seabury Press.

Goodman, C., Knight, D., Machen, I. and Hunt, B. 1998: Emphasising terminal care as district nursing: a helpful strategy in a purchasing environment? Journal of Advanced Nursing 28, 491-98.

Heidegger, M. 1962: Being and time. (transl MacQuarne, J. and Robinson, E.). New York: Harper \& Row.

Hoover, J. 2002: The personal and professional impact of undertaking an educational module on human caring. Journal of Advanced Nursing 37, 79-86.

Kitson, A. 1993: Formalising concepts related to nursing and caring. In Nursing: art and science. London: Chapman and Hall.

Leininger, M.M. 1988: Leininger's theory of nursing: cultural care diversity and universality. Nursing Science Quarterly 1, 15260.

Murray, R. 1998: Measurement of the effect of participation in a medical humanities group on the practice of physiotherapists. Physiotherapy 84, 473-79.

Motor Neurone Disease Association 2000: MND resource file. Northampton: MNDA.

Morse, J., Solberg, S.M., Neander, W.L., Bottoroff, J.L. and Johnson, J.L. 1990: Concepts of caring and caring as a concept. Advances in Nursing Science 13, 1-14.

Nolan, M.R. and Grant, G. 1989: Addressing the needs of informal carers; a neglected area of nursing practice. Journal of Advanced Nursing 14, 950-61.

Oliver, D. 1995: Motor neurone disease - a family affair. London: Sheldon Press.

Outhwaite, W. 1987: New philosophies of social science. Basingstoke: Macmillan Education.

Paley, J. 2001: An archaeology of caring knowledge. Journal of Advanced Nursing 36, 188-98.

Ray, C., Fisher, J. and Wisniewski, T.K.M. 1996: Surgeons' attitudes towards breast cancer, its treatment and their relationship with patients. Journal of Psychosocial Oncology 4, 33-43.

Roach, S. 1992: The human act of caring, revised edition. Ottawa: Canadian Hospital Association Press.

Robinson, I. and Hunter, M. 1998: Motor neurone disease. London: Routledge.

Small, N. and Rhodes, P. 2000: Too ill to talk? London: Routledge.

Stott, N.C.H., Rees, M., Rollick, S., Pill, R.M. and Hackett, P. 1996: Professional responses to innovation in clinical method: diabetes care and negotiating skills. Patient Education and Counselling 29, 67-73.

Thorne, S.E., Ternulf Nyhlin, K. and Paterson, B.L. 2000: Attitudes toward patient expertise in chronic illness. International Journal of Nursing Studies 37, 303-11.

Twigg, J. 1997: Deconstructing the 'social bath': help with bathing at home for older and disabled people. Journal of Social Policy 26, 211-32.

Walters, A.J. 1995: The phenomenological movement: implications for nursing research. Journal of Advanced Nursing 22, 791-99.

Watson, J. 1985: Nursing: human science and human care. A theory of nursing. New York: Appleton-Century Croft.

Watson, R., Deary, I.J. and Lea, A. 1999: A longitudinal study into the perceptions of caring among student nurses using multivariate analysis of caring dimensions inventory. Journal of Advanced Nursing 30, 1080-89.

Wikstrom, B. 2001: Works of art; a complement to theoretical knowledge when teaching nursing care. Journal of Clinical Nursing 10, 25-32.

Wilson, P.M. 2001: A policy analysis of the expert patient in the United Kingdom: self-care as an expression of pastoral power? Health and Social Care in the Community 9, 134-42.

Yam, B.M.C. and Rossiter, J.C. 2000: Caring in nursing: perceptions of Hong Kong nurses. Journal of Clinical Nursing 9, 293-302. 